\title{
For long-term economic development, only skills
}

\section{matter}

\section{Economic growth determines a nation's long-term economic well- being and crucially depends on skills}

Keywords: growth, cognitive skills, knowledge capital, teacher quality, Sustainable Development Goals, schools

\section{ELEVATOR PITCH}

Politicians typically focus on short-term economic issues; but, a nation's long-term economic well-being is directly linked to its rate of economic growth. In turn, its growth rate is directly linked to the economically relevant skills of its population. Until recently, however, economists have found it hard to confirm this through empirical analysis because of difficulties in measuring the skills of different societies. International tests of mathematics and science achievement now offer reliable measures of a population's relevant cognitive skills.

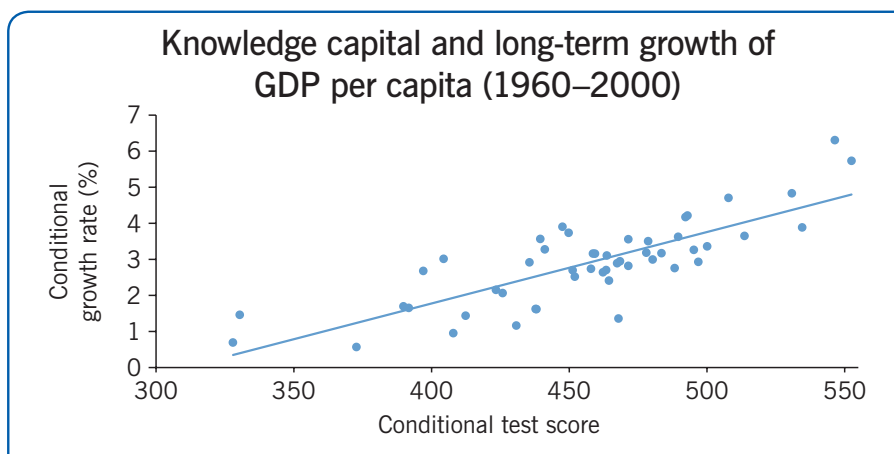

Note: Each dot represents a country. The underlying regression model includes GDP per capita in 1960 and years of school in 1960. Source: [1].

\section{PROS AND CONS}

\section{Pros}

$\oplus$ Economic growth differences are readily explained by disparities in the knowledge capital of nations.

† Correct measurement of skills is important and helps identify useful areas of policy improvement.

๑ Economic growth generates GDP gains that allow countries to meet a variety of societal goals.

() A trade-off between income growth and the equality of incomes is not inevitable.

\section{Cons}

- Skill improvement is difficult because alternative schooling policies are controversial.

- Economic results do not appear until far in the future.

- Faster economic growth may mean greater inequality.

- There are no analyses considering the lowest income countries.

\section{AUTHOR'S MAIN MESSAGE}

A country's development depends on its economic growth, and countries that foster high levels of skills in their population will thrive in the long term. The gains in GDP related to skill improvements lead to substantial gains in GDP per capita, which can be used to finance other objectives, such as those found in the UN's Sustainable Development Goals. Analysis shows that there are enormous potential economic gains from improving the quality of schools. This finding justifies substantial schooling reforms. 


\section{MOTIVATION}

Differences in economic growth across nations produce dramatically different outcomes. As a simple example, between 1960 and 2000, South Korea's per capita real GDP grew at an average rate of just under $6 \%$, leading to an income level in 2000 that was ten times greater than in 1960. Over the same period, New Zealand's GDP per capita grew at just over 1\% per year, leading to a GDP per capita in 2010 that was only 1.6 times greater than that in 1960, and its GDP per capita was overtaken by Korea by 2015.

\section{DISCUSSION OF PROS AND CONS}

\section{Empirical growth modeling}

Appreciation for the importance of long-term economic growth has changed over time, with macroeconomists historically focusing more on the short-term impacts of business cycles, typically encompassing various monetary and fiscal policies. However, recent advances in the analysis of economic growth have enabled researchers to examine more confidently the potential drivers of long-term outcomes, thus restoring some balance to these discussions.

Beginning in the 1990s, the intensity of work on both theoretical and empirical analyses of economic growth increased. There was a concerted effort to explain why some nations grew faster than others. Studies based on cross-country regression analyses investigated a wide range of potential causes, from economic institutions such as openness to trade to the prevalence of malaria. However, no matter what other explanations were included, empirical modeling invariably included some measure of human capital.

The most common measure of human capital is simply the average years of schooling of a country's adult population. This is in part because of its prevalence in international data sets. But it also has empirical justification from the power of school attainment to explain income differences among individuals-one of the world's most successful empirical models, developed by Jacob Mincer, supports this result [2].

In an international context, Figure 1 shows the relationship between long-term growth of GDP per capita between 1960 and 2000 and the average years of schooling in each country in 1960 [1]. (The axis label "Conditional" refers to inclusion in the underlying statistical model behind this picture of the initial level of GDP per capita in each country, reflecting the fact that it is easier to grow fast when starting behind because it is only necessary to copy what more advanced nations are doing). There is an obvious positive relationship between school attainment and growth, and this has fed into most other empirical studies.

Nevertheless, fairly soon after the initial growth modeling efforts took place in the 1990s, skepticism about the empirical findings began to grow. The dominant theme was that the empirical work did not reflect any causal relationship. While there might be a correlation between various measures of education and economic growth, this could not be taken as a reflection of the causal impact of factors that might be manipulated through policy. This argument was particularly salient for human capital, because as additional income from economic growth accrued, countries would invest in more schooling-suggesting that reverse causation was a serious threat [3], [4]. 
-Figure 1. School attainment and long-term growth of GDP per capita (1960-2000)

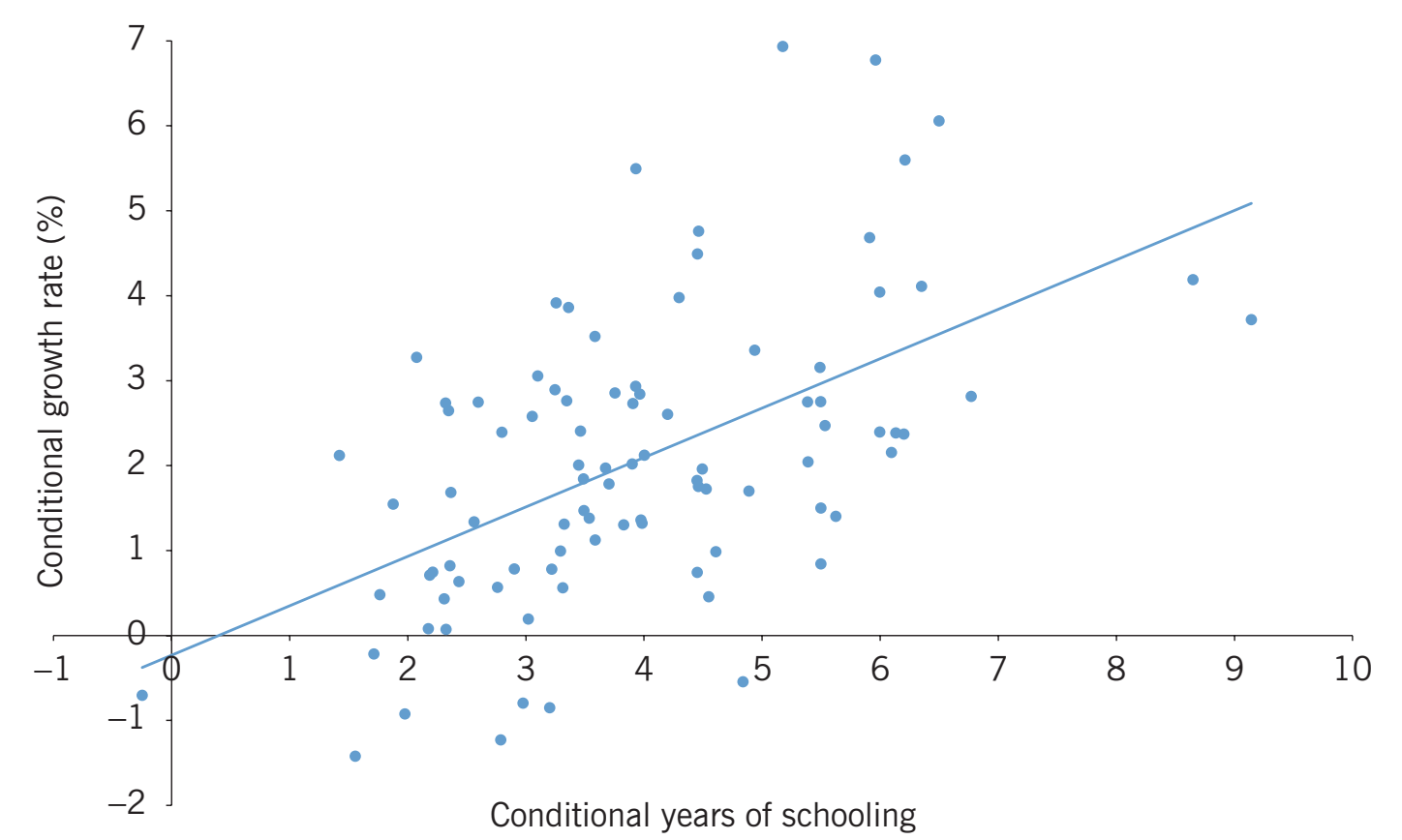

Note: Each dot represents a country. "Conditional" refers to the underlying regression model that includes GDP per capita in 1960.

Source: Hanushek, E. A., and L. Woessmann. The Knowledge Capital of Nations: Education and the Economics of Growth. Cambridge, MA: MIT Press, 2015 [1].

This skepticism about the ability to provide reliable empirical estimates of the determinants of economic growth led many people to reject the whole endeavor. If one could not verify the causal nature of the growth relationship, it did not make sense to pursue the topic.

\section{Measuring skills: Knowledge capital}

Much of the difficulty in convincingly explaining growth differences appears related to the measurement of human capital. The focus on school attainment provides a distorted picture of skill differences among individuals and across nations. Even though years of schooling is the most common measure of human capital, there are obvious concerns about its validity in an international context. For example, on the surface, few would think that a year of schooling in Peru produced the same learning and skills as a year of schooling in Japan, but this is the implicit assumption of standard growth modeling. Beyond the issue of differences in school quality, almost all micro analyses of achievement differences across populations recognize that schooling is just one factor in the learning process, and that families, peers, health, neighborhoods, and other factors are also important-indeed, perhaps even more important.

An alternative is to measure skills directly. Since the mid-1960s, a series of international tests of mathematics and science has allowed direct comparisons of people's cognitive skills in different countries. When scores from the 12 separate testing occasions between 1965 and 2003 are aggregated into a single national measure of skills, it is possible to construct a more appropriate measure of human capital-a measure that has been 
called "knowledge capital" to distinguish it from the, more common, years of schooling measure.

The illustration on page 1 shows the relationship between knowledge capital and growth between 1960 and 2000 for the 50 countries with data on both knowledge capital and economic growth. This figure, which parallels Figure 1 (and is conditional on the initial levels of GDP per capita and of years of schooling), summarizes the very strong relationship that exists using the knowledge capital of each country. First, most countries fall close to the growth line. The regression of growth on knowledge capital (and initial level of income) explains three-quarters of the cross-country variation in long-term growth rates, as compared to one-quarter when using years of schooling. Second, the relationship is very stable when other measures of country attributes are added, including geographical location, political stability, capital stock, and population growth. These specification tests rule out the problems attributable to omitted causal factors noted in prior growth work. Third, the relationship is very strong-a one standard deviation increase in knowledge capital is associated with a $2 \%$ per year faster growth rate. Two percentage points is approximately equivalent to the advantage in growth rates of East Asian countries over the OECD average, or, on the other side, the disadvantage of Latin American countries compared again to the OECD average.

\section{Do skills cause growth?}

It is of paramount importance to establish credibly that the relationship between skills and growth is causal in nature. While it is impossible to answer all possible threats to establishing this, a series of varied analyses provide strong support for a causal interpretation of this relationship. Detailed analyses are available elsewhere, but the quick summary immediately below provides an overview to both the analysis and any potential remaining issues [5].

First, there is little reason to think that higher student achievement is caused by economic growth. Previous analyses have found little consistent impact of additional education spending on achievement outcomes, so it is unlikely that the relationship between knowledge capital and economic growth comes from growth-induced resources lifting student achievement.

Second, because the basic analysis relates growth rates over the period 1960-2000 to test scores measured roughly over the same period, the possibility of reverse causality again arises. By relating test scores through 1984 to economic growth after 1985 (until 2009), the positive relationship of test scores with subsequent growth rates is almost twice that for the entire period. In other words, looking at just prior test scores on later growth (where reverse causality is impossible) not only strengthens the causal interpretation but also suggests increased importance on skills in the more recent period.

Third, because of the possibility of omitted variables, one can focus on exogenous variation arising directly from differences in schooling institutions across countries. Instrumental variable estimation based on the characteristics of each country's school system (e.g. exit examinations, school autonomy, relative teacher salaries, and private schooling) yields essentially the same results as found in the illustration on page 1 . The similarity of the results supports the causal interpretation of the effect of cognitive skills on growth, as well as the conclusion that schooling policies can have direct economic returns. The argument 
would collapse, however, if countries that adopted good characteristics for schools also had strong growth for other reasons.

Fourth, it is likely that countries with good economies also have good school systems. In this case, achievement could simply be a reflection of other important aspects of the economy, and not the driving force behind growth. One simple way to test this is to consider the implications of differences in measured skills just for immigrants within the US economy. This can be done by comparing US immigrants who have been educated in their home countries with immigrants educated only in the US, eliminating both the potential impact of country-level economic institutions and cultural factors. This type of comparison finds that the cognitive skills seen in the immigrant's home country lead to higher incomes, but only if the immigrant was educated in the home country. Immigrants from the same home country but schooled in the US see no economic return to homecountry test scores-a finding that pinpoints the value of skills as opposed to countryspecific institutions or culture.

Finally, perhaps the toughest test of causality is relating changes in test scores over time to changes in growth rates. If test-score improvements actually do increase growth rates, analyses of this relationship should show it. While only 12 countries have participated in testing at sufficiently different points over the past half century, it appears that gains in test scores over time are very closely related to the gains in annual growth rates over time.

Each approach to determining causation is subject to its own uncertainty. Nonetheless, the combined evidence consistently points to the conclusion that differences in cognitive skills lead to significant differences in economic growth.

Since the causality tests concentrate on the impact of schools, the evidence suggests that school policy, if effective in raising cognitive skills, can be an important force for economic development. While other factors-culture, health, and so forth-may affect the level of cognitive skills in an economy, schools clearly contribute to the development of human capital. This fact is important because schools can be more readily affected by public policy than those other major inputs to human capital.

\section{School quality and school quantity in development}

One other aspect of the relationship between schooling and long-term growth is important, namely school quality. Figure 2 shows the impact of years of schooling on growth after conditioning for learning in the country; i.e. after allowing for differences in knowledge capital. More years of schooling in a system that is not well designed to enhance the development of skills will have little effect. Once what is actually learned is taken into account, school attainment is not correlated with growth.

This observation about attainment and growth relates directly to major policy initiatives. In 2000, the United Nations (UN) developed a set of targets for world development called the Millennium Development Goals (MDGs). The MDGs covered various policy areas, but the education goal was clear: "to ensure that, by 2015, children everywhere, boys and girls alike, will be able to complete a full course of primary schooling."

While this goal of access was not met fully by 2015 , considerable improvement was seen across developing countries. Between 1999 and 2012, net enrollment in primary schools 
Figure 2. The growth effect of school attainment after allowing for knowledge capital

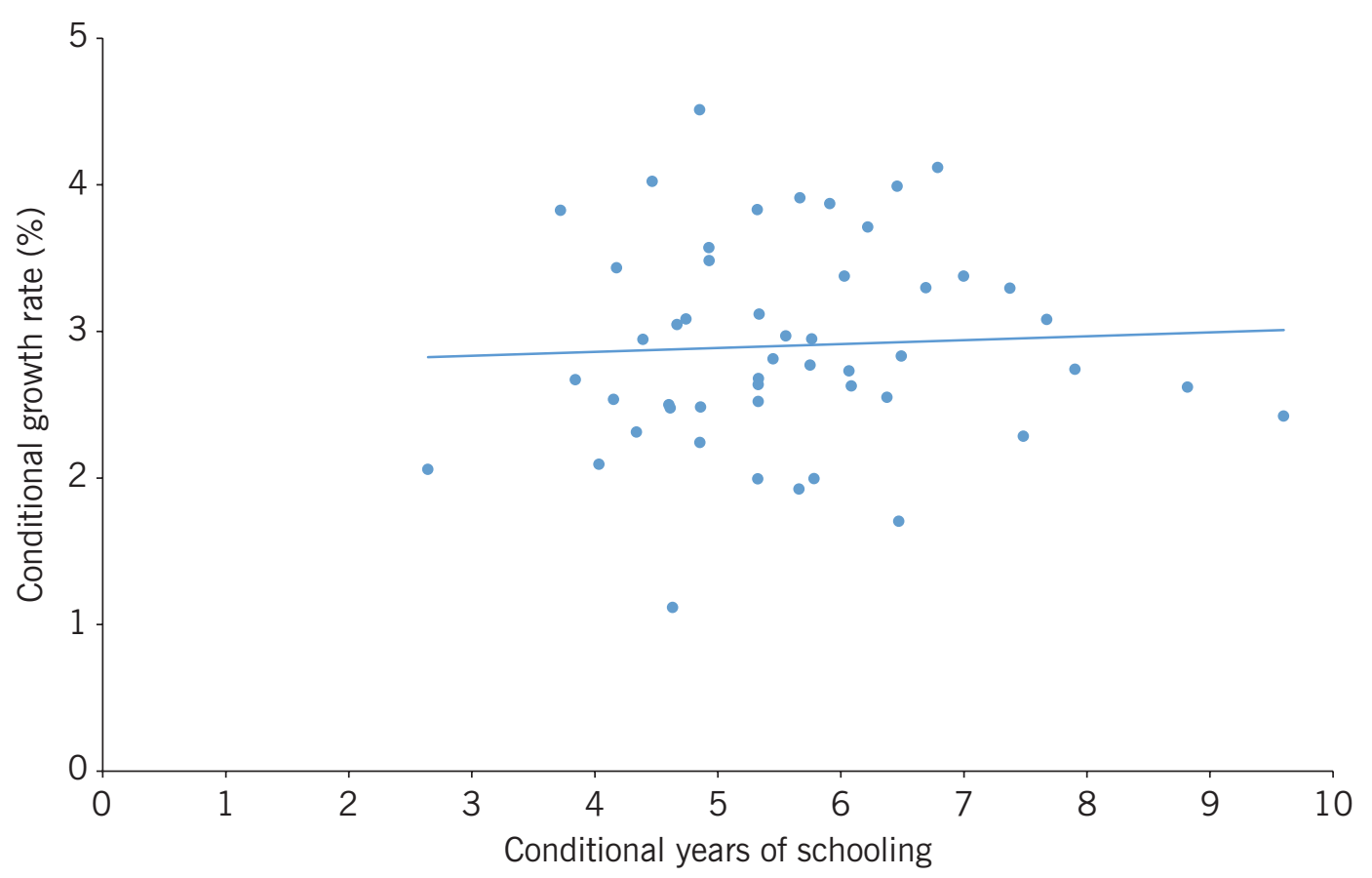

Note: Each dot represents a country. The underlying regression model of long-term growth in GDP per capita (1960-2000) includes GDP per capita in 1960 and knowledge capital.

Source: Hanushek, E. A., and L. Woessmann, The Knowledge Capital of Nations: Education and the Economics of Growth. Cambridge, MA: MIT Press, 2015 [1].

in developing countries increased from $82 \%$ to $90 \%$ [6]. The gains in South and West Asia (from $78 \%$ to $94 \%$ ) and sub-Saharan Africa (from 59\% to 79\%) were particularly dramatic over this short period. But, there is little evidence that these gains in attendance were matched with commensurate gains in learning. While relatively few developing countries have participated in the international achievement tests-the Programme for International Student Assessment (PISA) and Trends in International Mathematics and Science Study (TIMSS)-there has been little sign of improvement in performance for those that have participated, and they remain stuck at the bottom of the international rankings. Further, even though a number of countries have expanded school access through conditional cash transfer programs that provide direct subsidies for school attendance, evaluations have provided little evidence that this has resulted in increased learning.

The UN developed a follow-on set of goals to the MDGs called the Sustainable Development Goals (SDGs). The SDGs, designed to be met by 2030, are both broader and more ambitious. They cover poverty, health, inclusion, and environmental sustainability. But, two of the goals ultimately represent the key to all the rest: strong growth and quality education. Strong growth in overall living standards is necessary to pay for the full set of ambitious SDGs; they would not be affordable at existing living standards even if very high taxes were levied on the small number of extremely rich people in developing countries. Moreover, as discussed previously, to obtain strong growth it is necessary to have a highquality education system.

The SDGs improved on the previous MDGs by including a mandate to "ensure inclusive and equitable quality education and promote lifelong learning opportunities for all." The 
inclusion of quality in the goal is a clear improvement over the prior goals that merely emphasized access, but the lack of defining a standard of quality opens the possibility that it will continue to be approached largely on an access basis.

To understand the difference between the "access approach" and the "quality approach," it helps to use the previous model of economic growth shown in the illustration on page 1 to assess how various improvements in achievement and access would be expected to affect the incomes of individual countries. The impact obviously depends on the current level of economic and educational development of a country. It also depends on how quickly any educational improvement can be accomplished, because this, in turn, determines when more skilled workers can become a sizable part of the labor force.

A straightforward projection comes from taking the SDGs seriously. If one assumes that quality education means students achieve a set of basic skills, then it is possible to translate the education goal into a level of achievement that should be expected of students. Specifically, using the standards developed by PISA, it is possible to define basic skills as: 15-year-olds meeting Level 1 (the lowest of six performance levels) for mathematics and science. For mathematics, the description is: "At Level 1, students can answer questions involving familiar contexts where all relevant information is present and the questions are clearly defined. They are able to identify information and to carry out routine procedures according to direct instructions in explicit situations. They can perform actions that are almost always obvious and follow immediately from the given stimuli" [7]. Roughly $20 \%$ of 15 -year-olds in the OECD cannot reliably solve Level 1 mathematics problems, while as many as $90 \%$ in low-income countries like Ghana cannot.

To place the potential gains in perspective, consider three possible scenarios: (i) Quality of schools is increased to Level 1 for all students in school by 2030, but access does not expand; (ii) Access expands so that all students regularly complete lower secondary school by 2030, but quality does not change from current levels; (iii) There is universal access, and all students can achieve Level 1.

An important element of any new schooling policy would be the dynamics of improvement. It takes time until schools can be improved (here, until 2030). It also takes time for students to enter the labor market and for new, higher-skilled workers to become a substantial portion of the labor force. For this simulation analysis, retirees (those who have worked at least 40 years) are replaced with new, more skilled workers, and the annual growth that corresponds to the average quality of workers at each point in time is simulated. It is then possible to calculate the difference in GDP with and without more skilled workers. This simulation is conducted over 80 years (the life expectancy of somebody born today), and the gains in future GDP are discounted back to today at 3\% to give the present value of benefits from improved knowledge capital.

In estimating the impact of expanded access, it is important to know the skill levels of those not in school. Since those out of school are not tested, the projections assume that they would, on average, fall into the 25 th percentile of all tested students, implying that giving them access would bring them up, on average, to students in the 50th percentile. Thus, for each country, it is possible to estimate the improvement in scores across the entire country. Similarly, with no expansion in access, any given improvement for school children must be discounted for those not attending school.

It is possible to project future growth for 76 countries where there are data on their current achievement levels [8]. Figure 3 shows the results of each scenario's projections 


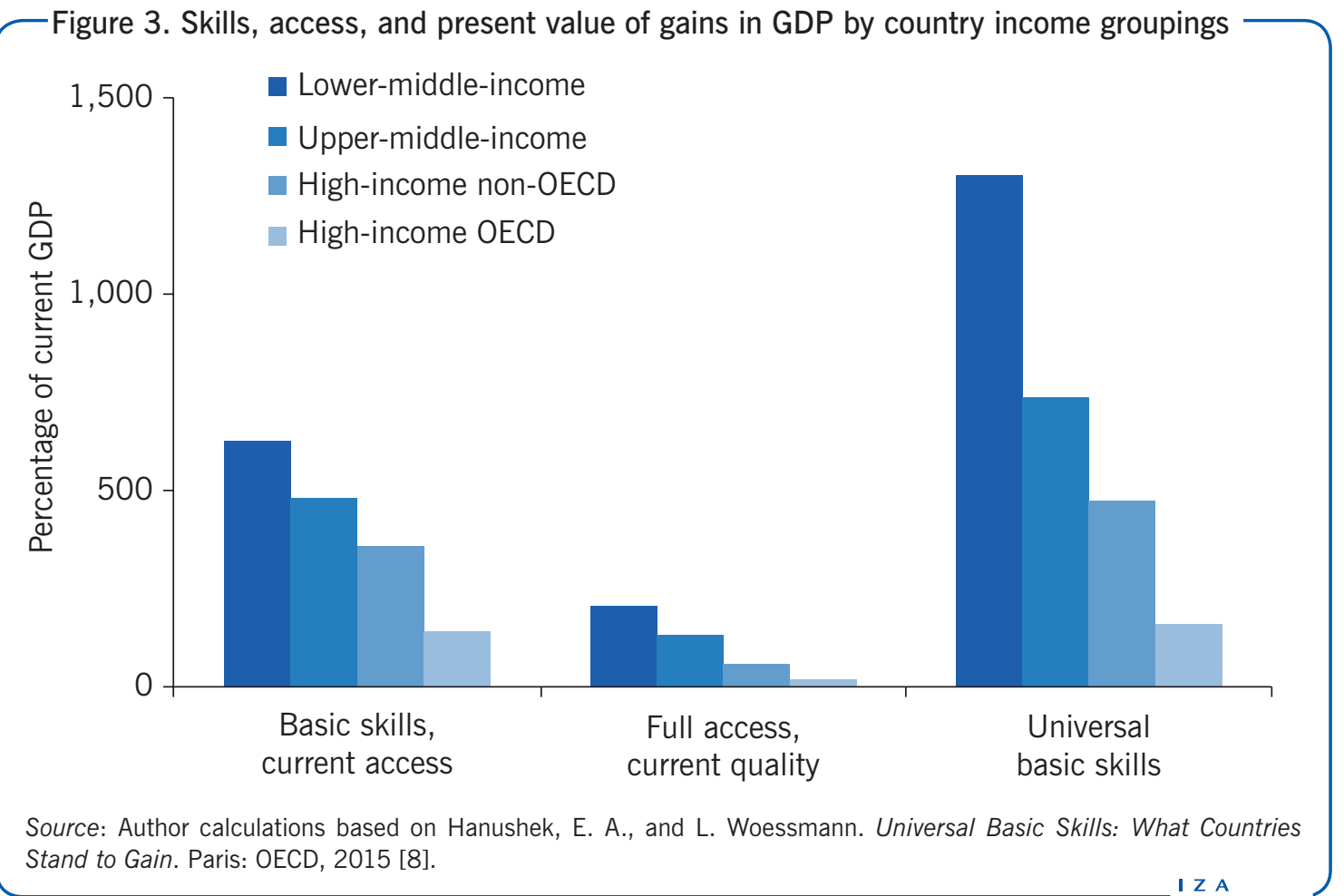
Stand to Gain. Paris: OECD, 2015 [8].

for groupings of countries by income level. The lowest income countries (such as Armenia, Ghana, Honduras, and Indonesia) would, on average, receive a present value return from reaching basic skill levels for those currently in school worth more than six times their current GDP. Countries in the next level of income (such as Argentina, Mexico, Thailand, and Turkey) would receive gains of almost five times their current GDP. The high-income non-OECD countries, which include, among others, a number of Arab oil countries, would receive gains over 3.5 times their current GDP, while the high-income OECD countries would average returns almost 1.5 times their current GDP levels. In other words, the quality imperative applies worldwide, not just to developing countries.

The gains from just expanding access at current quality levels, shown in the middle columns of Figure 3, yield much smaller average benefits, even for the least developed countries where access currently falls far short of universal. The evidence suggests that individuals with low skill levels will have trouble participating in modern economies.

Significantly larger economic improvements come from achieving universal basic skillsi.e. ensuring full access to schools of sufficient quality for all. In the lower-middle-income countries, the average return from this is over 13 times current GDP levels. Of course, lower-income countries will have difficulty achieving the improvements in outcomes by 2030 , but this shows the kinds of benefits that could accrue as a result of quality improvements.

\section{Skills and individual earnings}

Improving the skills of low-skilled individuals not only affects a country's growth, but also works to improve the distribution of incomes. Individuals' skills are rewarded in the labor 
market, and making sure that all societal members have the ability to participate in the modern economy will raise the bottom of the income distribution [9]. Indeed, returns to skills are highest in countries that are fast-growing, because skills give individuals the ability to adapt to changes in the economy [10]. The reverse is also true: with rapid growth there are also larger punishments in terms of worsened labor market prospects for those with few skills, potentially increasing overall inequality.

Implicitly, there need not be any trade-off between growth and equality when growth comes from raising the skills of the population (unless of course the skills of the elite are raised disproportionately) [1].

\section{LIMITATIONS AND GAPS}

The evidence presented in this article does not say anything about how quality improvement should be accomplished in schools. Some countries, both developed and developing, have shown considerable improvement over the past two decades in terms of learning quality, while others have seen outcomes from their schools fall. Significant work has been done on understanding some of the underlying factors for this disparity, but more is clearly required [11].

Further work on the details of the growth analysis presented above would be beneficial. In particular, refining the measures of skills, including going beyond just country averages in knowledge capital, would help in developing appropriate policies. Further consideration of how skills interact with other aspects of national economies, such as overall economic institutions, may help to refine policy design and implementation.

It is important to recognize that the gains from educational improvement take time to accrue. The previous discussion shows that it is worth waiting for long-term economic results, but it implies that politicians and decision makers must take a long-term perspective, much like they might do with matters of the environment.

Additionally, the analysis, to date, has looked at some of the economically better off developing countries as well as the more developed countries of the world. Of the 76 countries currently studied, only seven are classified as lower-middle-income by the World Bank, and none are low income. This limited focus reflects the countries that have participated in recent international assessments. It is quite likely that those not tested tend to be countries with greater challenges, both economically and educationally. This leaves a substantial set of missing countries.

\section{SUMMARY AND POLICY ADVICE}

Economic development is a matter of growth, and growth depends on the productivity enhancing skills of a country's population. Fortunately, such skills can now be captured quite well by scores on international mathematics and science tests.

The impact of higher skills is very large, but years of schooling has little impact on growth once skills are accounted for. The clear implication is that, when a country expands its schooling system, it should ensure that the schools are high quality. Moreover, improvements over time in school quality are easily justified by the added income that they generate. 
The best way in which skills can be improved will vary according to a country's specific situation. Successful policies are likely to depend on both local capacity and local demands. Nevertheless, from a policy viewpoint, improving school quality is a clear avenue to achieve improved long-term growth. The unifying theme for policymakers to consider is to focus on the outcomes for individuals in terms of skills and not just the inputs such as the level of education in terms of years of schooling. Improving the quality of schools is the development imperative.

\section{Acknowledgments}

The author thanks an anonymous referee and the IZA World of Labor editors for many helpful suggestions on earlier drafts. Previous works of the author and Ludger Woessmann contain a larger number of background references for the material presented here and have been used intensively in all major parts of this article [1], [5], [8], [11], and [12].

\section{Competing interests}

The IZA World of Labor project is committed to the IZA Guiding Principles of Research Integrity.

The author declares to have observed these principles.

(c) Eric A. Hanushek 


\section{REFERENCES}

\section{Further reading}

Hanushek, E. A., S. J. Machin, and L. Woessmann (eds.). Handbook of the Economics of Education, Volume 5. Amsterdam: North Holland, 2016.

Hanushek, E.A., and D. D. Kimko. "Schooling, labor force quality, and the growth of nations." American Economic Review 90:5 (2000): 1184-1208.

Hanushek, E. A., and L. Woessmann. The High Cost of Low Educational Performance the Long-Run Economic Impact of Improving Pisa Outcomes. Paris: OECD, 2010.

\section{Key References}

[1] Hanushek, E. A., and L. Woessmann. The Knowledge Capital of Nations: Education and the Economics of Growth. Cambridge, MA: MIT Press, 2015.

[2] Mincer, J. "The distribution of labor incomes: a survey with special reference to the human capital approach." Journal of Economic Literature 8:1 (1970): 1-26.

[3] Levine, R., and D. Renelt. "A sensitivity analysis of cross-country growth regressions." American Economic Review 82:4 (1992): 942-963.

[4] Bils, M., and P. J. Klenow. "Does schooling cause growth?" American Economic Review 90:5 (2000): 1160-1183.

[5] Hanushek, E. A., and L. Woessmann. "Do better schools lead to more growth? Cognitive skills, economic outcomes, and causation." Journal of Economic Growth 17:4 (2012): 267-321.

[6] UNESCO. Education for All 2000-2015: Achievements and Challenges - EFA Global Monitoring Report 2014/5. Paris: OECD, 2015.

[7] OECD. PISA 2012 Results: What Students Know and Can Do - Student Performance in Mathematics, Reading and Science (Volume I). Paris: OECD, 2013.

[8] Hanushek, E. A., and L. Woessmann. Universal Basic Skills: What Countries Stand to Gain. Paris: OECD, 2015.

[9] Hanushek, E. A., G. Schwerdt, S. Wiederhold, L. Woessmann. "Returns to skills around the world: Evidence from PIAAC.” European Economic Review 73 (2015): 103-130.

[10] Hanushek, E. A., G. Schwerdt, S. Wiederhold, and L. Woessmann. "Coping with change: International differences in returns to skills." Economic Letters 153 (2017): 15-19.

[11] Hanushek, E. A., and L. Woessmann. "The economics of international differences in educational achievement.” In: Hanushek, E. A., S. Machin, and L. Woessmann (eds). Handbook of the Economics of Education, Vol. 3. North Holland: Amsterdam, 2011; pp. 89-200.

[12] Hanushek, E. A., and L. Woessmann. "The role of cognitive skills in economic development." Journal of Economic Literature 46:3 (2008): 607-668.

\section{Online extras}

The full reference list for this article is available from:

http://wol.iza.org/articles/for-long-term-economic-development-only-skills-matter

View the evidence map for this article:

http://wol.iza.org/articles/for-long-term-economic-development-only-skills-matter/map 